\title{
A Comparative Analysis of Psychological Disorders between Internet Addicted Students and Ordinary Internet Users in Zabol University of Medical Sciences
}

\author{
Hasan Ali Miri \\ MA Student of Educational Psychology, Department of Psychology, Zahedan Branch, Islamic Azad University, \\ Zahedan, Iran \\ Email: hjenaabadi@gmail.com
}

Received 2 November 2014; accepted 29 April 2015; published 29 September 2015

Copyright (C) 2015 by author and Scientific Research Publishing Inc.

This work is licensed under the Creative Commons Attribution International License (CC BY). http://creativecommons.org/licenses/by/4.0/

(c) (i) Open Access

\begin{abstract}
Nowadays, using the Internet, for academic and non-academic activities, is an integral part of students' daily life. Studies showed that excessive use of the Internet has negative effects on physical and mental health. The present research was conducted in order to compare the psychological disorders of Internet addicted students and ordinary Internet users in Zabol University of medical sciences. It applied a causal-comparative method. Through applying purposive sampling method, 252 undergraduate and postgraduate students of Zabol University of Medical Sciences were selected in May 2015. Data collection was performed using standard questionnaires of Young's Internet Addiction Test and the Symptom Check List 90-Revised (SCL-90-R). Data analysis was carried out using independent t-test with SPSS $_{21}$. Results indicated that the Internet addicted students, compared with ordinary Internet users had more psychological disorders. Considering the high prevalence of psychological disorders in the Internet addicted students, teaching appropriate use of the Internet to students is an important factor in controlling the Internet addiction.
\end{abstract}

\section{Keywords}

Internet Addiction, Psychological Disorders, Students 


\section{Introduction}

The term Internet addiction disorder was first used by Goldberg as excessive and damaging use of the Internet that included factors such as withdrawal symptoms as criteria to diagnosis this disorder [1]. Internet addiction or behavioral dependence on the Internet, regardless of being a mental problem or a social dilemma is a chronic, universal and recurrent phenomenon with serious physical, financial, family, social and mental injuries [2]. Internet addiction includes addiction to chat rooms, pornography and online gambling that can lead to the destruction of health of relationships, emotions and finally mind. It should be noted that long use of the Internet cannot be called addiction, but application of the Internet with the following consequences is addiction: a) application of the Internet associated with anxiety and distress, and b) application of the Internet with damaging effects on physical, psychological, economic, social, family relations and personal functions [3].

Several researchers have confirmed the prevalence of Internet addiction and its consequences in foreign university students [4]. Few studies have indicated the penetration of the Internet in Iran, the prevalence of Internet addiction and its consequences in various Iranian populations. Results of Nastizaee's study conducted in University of Sistan and Baluchestan showed higher levels of occurrence of depression and anxiety among students with Internet addiction compared to ordinary Internet users [5]. Results of Alavi et al. [6] confirmed the relationship of Internet addiction with all disorders in SCL-90. In this research study, obsession disorder and gender were the best predictors of Internet addiction. Internet addiction is associated with psychological, social and occupational problems. Research has indicated that Internet addiction has numerous negative consequences including educational failures, poor family relations, poor social structures, emotional problems, and psychological disorders [7]. The main objective of the present study was to compare the psychological disorders between Internet addicted students and ordinary Internet users in Zabol University of Medical Sciences.

Considering the fact that each year, higher education and families spend a great capital for health and education of students, training academically and mentally healthy, powerful and abled students who can achieve success and increase their capabilities as well as skills provides the society with efficient graduates and consequently, the future management of the country will be handed to graduates who have enough scientific stamina and power [8].

Mental health is a prerequisite of a useful, effective and satisfactory individual life and mental health of various classes of a society, especially effective and constructive groups, is the prerequisite of dynamicity, development and promotion of that society. Since students, in every society, have a special status and are considered as thoughtful and creative human force, paying attention to their mental health dimensions has a great effect on mental health of the total society. Since people, that are mentally healthy, can better apply their own subjective ability; therefore, securing their mental health, in order to learn and increase their scientific awareness, is of great importance [9].

Students studying at Zabol University of Medical Science, like other students, due to their education, use the Internet more than others. Thus, they are more exposed to development of Internet addiction. Youths are more interested in technology and their presence in online social networks is not ineffective in students' high orientation to the Internet and dependence to it.

Accordingly, the main aim of the present study was to compare the psychological disorders between Internet addicted students and ordinary Internet users at Zabol University of Medical Sciences.

\section{Research Objectives}

1) Comparing hypochondria between Internet addicted students and ordinary Internet users.

2) Comparing obsession between Internet addicted students and ordinary Internet users.

3) Comparing interpersonal sensitivity between Internet addicted students and ordinary Internet users.

4) Comparing depression between Internet addicted students and ordinary Internet users.

5) Comparing anxiety between Internet addicted students and ordinary Internet users.

6) Comparing aggression between Internet addicted students and ordinary Internet users.

7) Comparing social phobia between Internet addicted students and ordinary Internet users.

8) Comparing paranoid ideation between Internet addicted students and ordinary Internet users.

9) Comparing psychosis between Internet addicted students and ordinary Internet users.

10) Comparing psychological disorders between Internet addicted students and ordinary Internet users. 


\section{Methods}

This was a causal-comparative or an ex post facto research.

In the current study, 280 questionnaires were distributed among BA and MA students (continuous and discontinuous) studying at Zabol University of Medical Sciences, among which 28 questionnaires were eliminated due to lack of incomplete data or not being returned. Therefore, 252 questionnaires were analyzed, of which 158 individuals (62.69\%) were female and 223 individuals (88.5\%) were single and 138 individuals (54.8\%) were studying for a BA degree. Considering the Internet usage, 169 individuals $(67.1 \%)$ were placed in the group of Internet addicts (Table 1 ).

\subsection{Data Collection Tools}

To collect data, two standardized questionnaires were used.

a) Young's Internet Addiction Test (Y-IAT): This questionnaire contains 20 items assessing people’s addiction to the Internet. This questionnaire is designed based on a 5-point Likert type scale (from never to always) and is scored from 1 = never to 5 = always. Each respondent's minimum score on this questionnaire is 20 and the maximum score is 100.49 and lower scores indicate that the respondent is an ordinary Internet user and 49 and higher scores show that the respondent is an Internet addict.

b) The Symptom Check List-90-Revision: This scale includes 90 items on psychological disorders which contains 9 scales including somatic complaints (hypochondria), obsession, interpersonal sensitivity, depression, anxiety, aggression, social phobia, paranoid ideation, and psychosis. Responses to each item of this scale is designed based on a 5-point Likert type scale, i.e. never, rarely, sometimes, usually, and always (from never $=0$ to always $=4$ ). Higher scores on these 9 subscales and a higher overall score indicate more psychological disorder symptoms.

\subsection{Determining the Validity and Reliability of Data Collection Tools}

Validity refers to the extent to which the tool measures what it is designed to evaluate. To determine the validity of these questionnaires, content validity was used. In this regard, the validity of these questionnaires was confirmed by members of the faculty of Psychology of University of Sistan and Baluchestan assuring that these questionnaires measure the intended attributes and is valid.

Reliability is a technical characteristics of measuring tools indicating that the instrument tool, in the same condition, provides similar results. To assess the reliability, the pilot questionnaire was carried out on 30 subjects using Cronbach's alpha coefficient conducted by SPSS v.21. The results are as follows: work involvement (0.641), feeling driven to work (0.619), work enjoyment (0.644), work addiction (0.671), organizational commitment (0.72), and organizational citizenship behavior (0.81). This indicates that these questionnaires are reliable.

\subsection{Applied Statistical Methods}

In descriptive analysis of the obtained data, frequency, percentage, mean, and standard deviation were used. To examine and compare psychological disorders of university students whom were Internet addicts and ordinary users of the Internet, independent t-test was applied using SPSS v.21.

\section{Results}

- Psychological disorders of Internet addicted students is higher compared to those of ordinary users of the Internet.

\begin{tabular}{|c|c|c|c|c|c|}
\hline \multicolumn{2}{|c|}{ Variable } & \multirow{2}{*}{$\begin{array}{c}\text { Frequency (percentage) } \\
158(62.69 \%)\end{array}$} & \multicolumn{2}{|c|}{ Variable } & \multirow{2}{*}{$\begin{array}{c}\text { Frequency (percentage) } \\
114(45.2)\end{array}$} \\
\hline Condor & Female & & Level of & BA & \\
\hline Gend & Male & 94 (37.31\%) & education & MA & 138 (54.8) \\
\hline \multirow{2}{*}{$\begin{array}{l}\text { Marital } \\
\text { status }\end{array}$} & Single & 223 (88.5\%) & Internet & Ordinary & 83 (32.9) \\
\hline & Married & 29 (11.5\%) & usage & Addict & $169(7.1)$ \\
\hline
\end{tabular}


The results of independent t-test conducted to examine this hypothesis is presented in Table 2.

Based on the results demonstrated in Table 2, the mean scores of addict university students and ordinary Internet users on psychological disorders are respectively 149.55 and 129.03 and these two groups' mean difference is 20.52. Moreover, the calculated t (3.74) with the degree of freedom of 250 is significant at the 0.000 level $(\mathrm{P}<0.01)$. Accordingly, considering Internet addicted students' higher mean score on psychological disorders, it can be concluded that addicted students, compared to students who are ordinary users of the Internet, experience more psychological disorders.

- Hypochondria of Internet addicted students is higher compared to that of ordinary users of the Internet.

The results of independent t-test conducted to examine the second hypothesis is presented in Table 3.

Considering the results demonstrated in Table 3, the mean scores of addict university students and ordinary Internet users on hypochondria are respectively 19.43 and 16.92 and these two groups' mean difference is 2.51 . Moreover, the calculated t (2.88) with the degree of freedom of 250 is significant at the 0.004 level $(\mathrm{P}<0.05)$. Accordingly, considering the Internet addicted students' higher mean score on hypochondria, it can be concluded that addict students, compared to students who are ordinary users of the Internet, experience more hypochondria.

- Obsession of Internet addicted students is higher compared to that of ordinary users of the Internet.

The results of independent t-test conducted to examine the third hypothesis is presented in Table 4.

With regard the results demonstrated in Table 4, the mean scores of addict university students and ordinary Internet users on obsession are respectively 19.06 and 17.04 and these two groups' mean difference is 2.02. Moreover, the calculated t (2.49) with the degree of freedom of 250 is significant at the 0.013 level $(\mathrm{P}<0.05)$. Accordingly, considering the Internet addicted university students' higher mean score on obsession, it can be concluded that addict students, compared to students who are ordinary users of the Internet, have higher levels of obsession.

- Interpersonal sensitivity of Internet addicted students is higher compared to that of ordinary users of the Internet.

The results of independent t-test conducted to examine the fourth hypothesis is presented in Table 5.

Given the results presented in Table 5, the mean scores of addict university students and ordinary Internet users on interpersonal sensitivity are respectively 18.3 and 16.28 and these two groups' mean difference is 2.02 .

Table 2. Comparing psychological disorders of Internet addicted students and ordinary Internet users.

\begin{tabular}{cccccccc}
\hline Internet use & $\mathrm{N}$ & $\mathrm{M}$ & Mean difference & $\mathrm{SD}$ & $\mathrm{Df}$ & $\mathrm{T}$ & $\mathrm{P}$ \\
\hline Ordinary & 83 & 129.03 & -20.52 & 49.92 & & & \\
Addict & 169 & 149.55 & & 35.68 & & -3.74 & 0.000 \\
\hline
\end{tabular}

Table 3. Comparing hypochondria of Internet addicted students and ordinary Internet users.

\begin{tabular}{cccccccc}
\hline Internet use & $\mathrm{N}$ & $\mathrm{M}$ & Mean difference & $\mathrm{SD}$ & $\mathrm{df}$ & $\mathrm{T}$ & $\mathrm{P}$ \\
\hline Ordinary & 83 & 16.92 & -2.51 & 7.28 & & & \\
Addict & 169 & 19.43 & & 6.03 & & -2.88 & 0.004 \\
\hline
\end{tabular}

Table 4. Comparing obsession of Internet addicted students and ordinary Internet users.

\begin{tabular}{cccccccc}
\hline Internet use & $\mathrm{N}$ & $\mathrm{M}$ & Mean difference & $\mathrm{SD}$ & $\mathrm{df}$ & $\mathrm{T}$ & $\mathrm{P}$ \\
\hline Ordinary & 83 & 17.04 & -2.02 & 7.3 & & & \\
Addict & 169 & 19.06 & & 5.32 & & -2.49 & 0.012 \\
\hline
\end{tabular}

Table 5. Comparing interpersonal sensitivity of Internet addicted students and ordinary Internet users.

\begin{tabular}{cccccccc}
\hline Internet use & $\mathrm{N}$ & $\mathrm{M}$ & Mean difference & $\mathrm{SD}$ & $\mathrm{df}$ & $\mathrm{T}$ & $\mathrm{P}$ \\
\hline Ordinary & 83 & 16.28 & -2.02 & 7.03 & & & -2.45 \\
Addict & 169 & 18.3 & & 5.62 & & 0.015 \\
\hline
\end{tabular}


Moreover, the calculated t (2.45) with the degree of freedom of 250 is significant at the 0.015 level $(\mathrm{P}<0.05)$. Accordingly, considering the Internet addicted university students' higher mean score on interpersonal sensitivity, it can be concluded that addict students, compared to students who are ordinary users of the Internet, are more sensitive considering their interpersonal relations.

- Depression of Internet addicted university students is higher compared to that of ordinary users of the Internet.

The results of independent t-test conducted to examine this hypothesis is presented in Table 6.

With regard to the results presented in Table 6, the mean scores of the Internet addicted students and ordinary Internet users on depression are respectively 19.74 and 15.36 and these two groups' mean difference is 4.38 . Moreover, the calculated t (4.308) with the degree of freedom of 250 is significant at the 0.000 level $(\mathrm{P}<0.01)$. Accordingly, considering the Internet addicted students' higher mean score on depression, it can be concluded that addict students, compared to students who are ordinary users of the Internet, experience higher levels of depression.

- Anxiety of Internet addicted university students is higher compared to that of ordinary users of the Internet.

The results of independent t-test conducted to examine this hypothesis is presented in Table 7.

Considering the results represented in Table 7, the mean scores of addict university students and ordinary Internet users on anxiety are respectively 16.99 and 15.01 and these two groups' mean difference is 1.98 . Moreover, the calculated $t$ (2.29) with the degree of freedom of 250 is significant at the 0.023 level $(\mathrm{P}<0.05)$. Accordingly, considering the Internet addicted university students' higher mean score on anxiety, it can be concluded that addict students, compared to students who are ordinary users of the Internet, experience higher levels of anxiety.

- Aggression of Internet addicted students is higher compared to that of ordinary users of the Internet.

The results of independent t-test conducted to examine this hypothesis is presented in Table 8.

Given the results presented in Table 8, the mean scores of Internet addicted university students and ordinary Internet users on aggression are respectively 11.08 and 8.55 and these two groups' mean difference is 4.38 . Moreover, the calculated $t$ (3.71) with the degree of freedom of 250 is significant at the 0.000 level $(\mathrm{P}<0.01)$. Accordingly, considering the Internet addicted university students' higher mean score on aggression, it can be concluded that addict students, compared to students who are ordinary users of the Internet, are more aggressive.

- Social phobia of Internet addicted university students is higher compared to that of ordinary users of the Internet.

The results of independent t-test conducted to examine this hypothesis is presented in Table 9.

Given the results presented in Table 9, the mean scores of the Internet addicted university students and ordinary Internet users on social phobia are respectively 12.34 and 9.69 and these two groups' mean difference is 2.64. Moreover, the calculated $t$ (3.56) with the degree of freedom of 250 is significant at the 0.000 level $(\mathrm{P}<$

Table 6. Comparing depression of Internet addicted students and ordinary Internet users.

\begin{tabular}{cccccccc}
\hline Internet use & $\mathrm{N}$ & $\mathrm{M}$ & Mean difference & $\mathrm{SD}$ & $\mathrm{df}$ & $\mathrm{T}$ & $\mathrm{P}$ \\
\hline Ordinary & 83 & 15.36 & -4.38 & 7.08 & & & \\
Addict & 169 & 19.74 & & 7.82 & & -4.308 & 0.000 \\
\hline
\end{tabular}

Table 7. Comparing anxiety of Internet addicted university students and ordinary Internet users.

\begin{tabular}{cccccccc}
\hline Internet use & $\mathrm{N}$ & $\mathrm{M}$ & Mean difference & $\mathrm{SD}$ & $\mathrm{df}$ & $\mathrm{T}$ & $\mathrm{P}$ \\
\hline Ordinary & 83 & 15.01 & -1.98 & 7.32 & & & \\
Addict & 169 & 16.99 & & 6.44 & & & \\
\hline
\end{tabular}

Table 8. Comparing aggression of Internet addicted students and ordinary Internet users.

\begin{tabular}{cccccccc}
\hline Internet use & $\mathrm{N}$ & $\mathrm{M}$ & Mean difference & $\mathrm{SD}$ & $\mathrm{df}$ & $\mathrm{T}$ & $\mathrm{P}$ \\
\hline Ordinary & 83 & 8.55 & -2.23 & 4.14 & & & -3.71 \\
Addict & 169 & 11.08 & & 4.64 & & & \\
\hline
\end{tabular}


Table 9. Comparing social phobia of Internet addicted university students and ordinary Internet users.

\begin{tabular}{cccccccc}
\hline Internet use & $\mathrm{N}$ & $\mathrm{M}$ & Mean difference & $\mathrm{SD}$ & $\mathrm{df}$ & $\mathrm{T}$ & $\mathrm{P}$ \\
\hline Ordinary & 83 & 9.69 & -2.64 & 5.15 & & & \\
Addict & 169 & 12.34 & & 5.71 & & & \\
\hline
\end{tabular}

0.01). Accordingly, considering Internet addicted students' higher mean score on social phobia, it can be concluded that addict students, compared to students who are ordinary users of the Internet, experience more social phobia.

- Paranoid ideation of Internet addicted university students is higher compared to that of ordinary users of the Internet.

The results of independent t-test conducted to examine this hypothesis is presented in Table $\mathbf{1 0 .}$

Considering the results demonstrated in Table 10, the mean scores of the Internet addicted university students and ordinary Internet users on paranoid ideation are respectively 15.65 and 13.86 and these two groups' mean difference is 1.79. Moreover, the calculated t (2.26) with the degree of freedom of 250 is significant at the 0.025 level $(\mathrm{P}<0.05)$. Accordingly, considering the Internet addicted students' higher mean score on paranoid ideation, it can be concluded that addict students, compared to students who are ordinary users of the Internet, have more paranoid ideations.

- Psychosis of Internet addicted students is higher compared to that of ordinary users of the Internet.

The results of independent t-test conducted to examine this hypothesis is presented in Table 11.

Considering the results demonstrated in the above table, the mean scores of the Internet addicted university students and ordinary Internet users on psychosis are respectively 16.92 and 15.98 and these two groups' mean difference is 0.94 . Moreover, the calculated t (1.03) with the degree of freedom of 250 is not significant at the 0.3 level $(\mathrm{P}>0.05)$. Accordingly, while the Internet addicted university students' mean score on psychosis was higher than that of ordinary users, this difference is not significant. Therefore, it can be concluded that there is no significant difference between the Internet addicts and ordinary users considering their psychosis.

\section{Discussions}

- Psychological disorders of Internet addicted students is more than that of ordinary Internet users.

Studies conducted by Anderson [10] and Bloch [11] showed that students suffering from Internet addiction do not have necessary skills for establishing social relations and suffer from high mental vulnerability and low mental health. Nastizaee [5] also believed that Internet addiction is associated with symptoms such as anxiety, depression, irritability, restlessness, obsession, withdrawal, emotional disorders and social relations rupture. Moreover, findings of Cao et al. [12], exploring the prevalence of Internet addiction among Chinese adolescents, suggested that the Internet addicted group got higher scores on items such as neurosis, psychosis and lying than the control group.

- Hypochondria (somatic complaints) of Internet addicted students is more than that of ordinary Internet users.

This finding is consistent with the findings of Lee and Stapinski [13], Kruot et al. [14], and Hadadvand et al. [15]. Internet addiction is a chronic, universal and recurrent phenomenon with serious physical, financial, family, mental and social injuries. Studies show that cases such as alcohol and drug abuse, somatic disorders such as obesity, dry eyes, irregular meals, headache and backache are associated with Internet addiction [13]. Studies indicate that due to excessive use of the Internet, productivity and efficiency of users drops. They are late at work and work less. Lack of physical mobility and obesity along with symptoms such as backache and spasm are among the other consequences of this issue.

- Obsession of Internet addicted students is more than that of ordinary Internet users.

Yoldascan, et al. [16] aimed to determine the prevalence of obsession disorder and relevant factors among Turkish students and found that the prevalence of the disorder was higher in students compared to the general population.

- Interpersonal sensitivity of Internet addicted students is more than that of ordinary Internet users.

In a study conducted by Alavi et al. [6], results suggested that there was a positive and significant correlation between interpersonal sensitivity and Internet addiction. However, results indicated differences between gender, self-criticism and self-humiliation. Investigating the problems of interpersonal relationships is of significant 
Table 10. Comparing paranoid ideations of Internet addicted university students and ordinary Internet users.

\begin{tabular}{cccccccc}
\hline Internet use & $\mathrm{N}$ & $\mathrm{M}$ & Mean difference & $\mathrm{SD}$ & $\mathrm{df}$ & $\mathrm{T}$ & $\mathrm{P}$ \\
\hline Ordinary & 83 & 13.86 & -1.79 & 7.15 & & & \\
Addict & 169 & 15.65 & & 5.18 & & & \\
\hline
\end{tabular}

Table 11. Comparing psychosis of Internet addicted students and ordinary Internet users.

\begin{tabular}{cccccccc}
\hline Internet use & $\mathrm{N}$ & $\mathrm{M}$ & Mean difference & $\mathrm{SD}$ & $\mathrm{df}$ & $\mathrm{T}$ & $\mathrm{P}$ \\
\hline Ordinary & 83 & 15.98 & -0.94 & 7.43 & & & \\
Addict & 169 & 16.92 & & 6.34 & & & \\
\hline
\end{tabular}

importance in the preliminary diagnosis of personality disorders. On the other hand, the findings of some previously conducted studies suggested gender differences in personality traits. For example, men are far more aggressive than women or the relationship between age and personality problems and/or some gender differences in this regard [17].

- Depression of Internet addicted students is more than that of ordinary Internet users.

This finding is consistent with the results of Yen et al. [18], Jang et al. [19], Sanders et al. [20], MorahanMartin and Schumacher [21], and Nastizaeei [5]. The relationship between depression and Internet addiction is not readily apparent. In many studies depression is stated as an effect and in some studies as the cause of Internet addiction. Vizscheffer's study [22] also indicated that many Internet users apply the Internet as entertainment or as a tool to forget their problems. The use of the internet as a tool to fight problems, mitigating the feeling of disappointment, anxiety and depression or spending a long time on the Internet to find virtual friends or achieve imaginary and dreamy affairs that are impossible in real life by a number of Internet addicts are all among factors of being dependent to the Internet. King [23] indicated that Internet addicts are shy, timid and lonely with depression. Therefore, it can be argued that the precise cause of the relationship between depression and Internet addiction is not clear yet, maybe these disorders pave the way for Internet addiction or maybe these disorders arise from Internet addiction, i.e. Internet addicted individuals experience negative consequences such as depression and these issues need further studies [5].

- Anxiety of Internet addicted students is more than that of ordinary Internet users.

This findings is consistent with the results of Cao et al. [12], Yen et al. [18], Young et al. [24], Jang et al. [19], Ko et al. [25], Engelberg and Suberg [26], Yenjyko et al. [27], Yun et al. [28], Alavi et al. [6], and Nastizaee [5] who indicated that the level of anxiety of the Internet addicted students was more than that of other students. An explanation is that the cause of the relationship between anxiety and Internet addiction is not clear yet. High anxiety may have occurred before the Internet use, i.e. anxious individuals use the Internet as a way to escape depression. Research suggests that the uses of the Internet other than establishing relationships with others can predict depression and social anxiety in adolescents and youth [29].

- Aggression of internet addicted students is more than that of ordinary Internet users.

According to research findings carried out on the relationship of Internet addiction and aggression, it could be argued that probably the Internet provides individuals with an environment to be released from stress of the real world and this is associated with aggression. However, this requires longitudinal studies.

- Social phobia (social isolation) of Internet addicted students is more than that of ordinary Internet users.

This finding is consistent with the results of Yen et al. [18], Motamednejad [30], Sanders et al. [20], Kruot et al. [14], Shotton [31], Sajadian and Nadi [32], Alavi et al. [6], Zarbakhsh Bahri et al. [4], and Mashaieikh and Borjali [8]. Research indicates that for each hours of Internet use at home, half an hour of the direct relationship between a young individual and his/her family is diminished and this escape to an open and network community isolates him/her [30].

- Paranoid ideation of Internet addicted students is more than that of ordinary Internet users.

This finding is consistent with the results of Yen et al. [18] and Alavi et al. [6]. Among the main symptoms of paranoid personality disorder, lack of self-confidence and being suspicion to others can be mentioned such that other individuals' motivations are interpreted maliciously. Alavi et al. [6] compared psychological disorders of Internet addicted students and ordinary Internet users in university of Isfahan and found that paranoid ideations 
of the Internet addicted students was more than that of ordinary Internet users.

- There is not any significant difference between Internet addicted students and ordinary Internet users considering psychosis.

The above finding is consistent with the results of Alavi et al. [6]. It could be argued that since Internet addiction disorder is a kind of obsession, it seems that Internet addiction is more correlated with obsession rather than being considered as a severe psychotherapeutic symptom, like psychosis [6]. Excessive use of the Internet arises from the failure of controlling the Internet dependence and leads to anxiety and disorder in performing daily activities. Therefore, it could be argued that Internet addiction is the obsessive-compulsive result of using the Internet rather than being psychotic states of users.

\section{Conclusion}

According to the major finding of this study, it could be concluded that the Internet addicted students, compared to ordinary Internet users, experience more psychological disorders. The environmental factors (free access to and availability of the Internet and lack of supervision on how students use the internet) may start and cause the durability of psychological disorders and Internet addiction. It must be argued that the Internet is a safe tool in itself, but excessive and inappropriate use of it increases the risk of addiction to it. This phenomenon has caused a major problem for the mental health of the society. Internet addiction turns individuals to dependent people and affects their social relations. Excessive use of the Internet causes physical laziness, increases low mobility and reduces relations with others in the real world and as a result, it leads to social isolation. Moreover, individuals who highly use computers, are more likely to experience obesity, aggression, anxiety and slower learning processes and as a result they may experience the risk of mental health problems. Obviously, excessive use of the Internet is associated with specific mental and somatic issues and crises that if not diagnosed in time may seriously challenge mental health of the society. Maybe now that we are in the beginning decades of the Internet use, it is necessary to act more responsibly against its marginal issue. Therefore, all of the pros and cons of the Internet should be assessed in details and results of such assessments should be accurately used in policymaking. Since prevention precedes treatment, this phenomenon should be considered as a health problem which challenges most young people who are the next generation of the society. Through training young adults in families, schools and university, appropriate culture of effective use of the Internet should be provided. Generally, familiarity of the young generation with physical, behavioral and moral risks and inappropriate use of new technologies and improvement of value and moral foundations and creation of self-control are important for optimal use of new technologies.

\section{Recommendations}

\subsection{Recommendations Based on Research Findings}

- To get rid of Internet addiction, identification of pattern of excessive use of Internet is recommended. Therefore, awareness of basic symptoms of Internet addiction is necessary for university students and counselors for timely prevention and intervention in the progression of Internet addiction.

- University officials who are in charge of student health are recommended to be familiar with the phenomenon of Internet addiction as a health problem which often challenges young people and the future generation of the society and strive to pay attention to the culture of appropriate use of the Internet and training programs for students in families, universities and schools, and pay attention to solve the young generation's problem, planning for their entertainment in order to reduce the risk of Internet addiction.

\subsection{Recommendation for Further Research}

- Other researchers are suggested to investigate Internet addiction and conduct qualitative studies using interviews with addicts to the Internet in order to identify other relevant factors related to Internet addiction in our society.

- Conducting studies based on demographic characteristics (gender, age, profession, etc.) is also recommended.

\subsection{Limitations}

Among the limitations of the study, the population of the research could be pointed out which merely consisted 
of students of Zabol University of Medical Sciences, limited the generalizability of the results to other populations. The other limitation is the cross-sectional method used in the study. More longitudinal studies are needed to be conducted to directly measure the relationship between mental health and Internet addiction.

\section{References}

[1] Goldberg, L.R. (1976) Language and Personality: Toward a Taxonomy of Triat-Descriptive Terms. Istanbul Studies in Experimental Psychology, 12, 1-23.

[2] Shayegh, S., Azad, H. and Bahrami, H. (2009) Examining Internet Addiction and Its Relationship with Personality Traits in Adolescents in Tehran. Fundamentals of Mental Health, 11, 149-158.

[3] Omidvar, A. and Saremi, A.A. (2002) Internet Addiction: Description, Etiology, Prevention, Treatment and Scale of Internet Addiction Disorder Assessment. Tamrin Publication, Mashhad.

[4] Zarbakhsh Bahri, M.R., Rashidi, V. and Vaziri, M.J. (2012) Loneliness and Internet Addiction Students. Journal of Health Promotion Management, 2, 32-38.

[5] Nastizaee, N. (2009) The Relationship of General Health with Internet Addiction among Students of University of Sistan and Baluchestan. Tabib-e-Shargh, 11, 57-63.

[6] Alavi, S.S., Islami, M., Merasi, M.R., Najafi, M., Jannatifard, F. and Rezapour, H. (2010) Psychometric Properties of Young's Internet Addiction Test. Journal of Behavioral Sciences, 4, 183-189.

[7] Ko, Ch., Yen, J.Y. and Chen, C.C. (2005) Proposed Diagnostic Criteria of Internet Addiction for Adolescents. Journal of Nervous and Mental Disease, 193, 728-733. http://dx.doi.org/10.1097/01.nmd.0000185891.13719.54

[8] Mashaieikh, M. and Borjali, A. (2003) Examining the Relationship of Loneliness with the Use of the Internet in a Group of High School Students. Trends in Cognitive Sciences, 5, 39-44.

[9] Asadi, M., Adarvishi, S., Mahmoudi, M., Fayyasi, S. and Ghasemi Dahcheshmeh, M. (2014) The Relationship of Nursing Students’ Mental Health with Some Demographic Factors. Health and Care, 16, 79-88.

[10] Anderson, K.J. (2001) Internets Use among College Students an Exploratory Study. Journal of American College Health, 50, 21-26. http://dx.doi.org/10.1080/07448480109595707

[11] Bloch, J. (2002) Student/Teacher Interaction via Email: The Social Context of Internet Discourse. Journal of Second Language Writing, 11, 117-134. http://dx.doi.org/10.1016/S1060-3743(02)00064-4

[12] Cao, F., Su, L., Lin, T. and Gao, X. (2007) The Relationship between Impulsivity and Internet Addiction in a Sample of Chinese Adolescents. European Psychiatry, 22, 466-471. http://dx.doi.org/10.1016/j.eurpsy.2007.05.004

[13] Lee, B. and Stapinski, L. (2012) Seeking Safety on the Internet: Relationship between Social Anxiety and Problematic Internet Use. Journal of Anxiety Disorders, 26, 197-205. http://dx.doi.org/10.1016/j.janxdis.2011.11.001

[14] Kruot, R.E. and Gross, E.F. (2000) The Impact of Home Computer Use on Children Activity and Development. Future Child, 10, 123-144. http://dx.doi.org/10.2307/1602692

[15] Hadadvand, M., Karimi, L., Abbasi Validkandi, Z., Ramezanian, P. and Mehrabi, H. (2013) The Relationship between Internet Addiction and Sleep Problems among Students. Health and Care, 15, 39-49.

[16] Yoldascan, E., Ozenli, Y., Kutlu, O., Topal, K. and Bozkurt, A. (2009) Prevalence of Obsessive-Compulsive Disorder in Turkish University Students and Assessment of Associated Factors. BMC Psychiatry, 9, 40. http://dx.doi.org/10.1186/1471-244X-9-40

[17] Latifian, M. and Saif, D. (2007) Evaluating the Effects of Self-Awareness on Interpersonal Relationships Disorders of University Students. Journal of Humanities and Social Sciences of Shiraz University, 26, 137-150.

[18] Yen, J.K., Yen, C. and Yang, M. (2007) The Comorbid Psychiatric Symptoms of Internet Addiction: Attention Deficit and Hyperactivity Disorder, Depression, Social Phobia, and Hostility. Journal of Adolescent Health, 41, 93-98. http://dx.doi.org/10.1016/j.jadohealth.2007.02.002

[19] Jang, K.S., Hwang, S.Y. and Choi, J.Y. (2008) Internet Addiction and Psychiatric Symptoms among Korean Adolescents. Journal of Adolescent Health, 78, 165-182. http://dx.doi.org/10.1111/j.1746-1561.2007.00279.X

[20] Sanders, C.E., Tiffany, M., Field, M.D. and Kaplan, M. (2000) The Relationship of Internet Use to Depression and Social Isolation among Adolescents. Adolescence, 35, 237-242.

[21] Morahan-Martin, J. and Schumacher, P. (2003) Loneliness and Social Uses of the Internet. Computers in Human Behavior, 19, 659-671. http://dx.doi.org/10.1016/S0747-5632(03)00040-2

[22] Vizscheffer, F. (2005) Examining the Severity of Internet Addiction in Users of Internet Cafes in Lar. Fundamentals of Mental Health, 7, 27-33.

[23] Jafari, N. and Fatehizade, M. (2012) The Relationship between Internet Addiction and Depression, Anxiety, Stress and 
Social Phobia in Students of Isfahan University. Scientific Journal of Kurdistan University of Medical Sciences, 17, 90-101.

[24] Young, K.S. (2004) Internet Addiction. American Behavioral Scientist, 48, 402-415. http://dx.doi.org/10.1177/0002764204270278

[25] Ko, C., Yen, J.Y., Chen, C.C. and Yen, C.F. (2008) Psychiatric Comorbidity of Internet Addiction in College Students: An Interview Study. CNS Specter, 13, 147-153.

[26] Engelberg, E. and Sjoberg, L. (2004) Internet use, Social Skills, and Adjustment. Behavior Cyberpsychology, 7, 41-47. http://dx.doi.org/10.1089/109493104322820101

[27] Yenjyko, C.H., Yen, F., Chen, S.H., Chung, W.L. and Chen, C.H. (2008) Psychiatric Symptoms in Adolescents with Internet Addiction: Comparison with Substance Use. Psychiatry and Clinical Neurosciences, 62, 9-16. http://dx.doi.org/10.1111/j.1440-1819.2007.01770.x

[28] Yun, J.U., Ko, C.H., Yen, C.F., Wu, H.Y. and Yang, M.J. (2007) The Comorbid Psychiatric Symptoms of Internet Addiction: Attention Deficit and Hyperactivity Disorder, Depression, Social Phobia and Hostility. Journal of Adolescence Health, 41, 93-98. http://dx.doi.org/10.1016/j.jadohealth.2007.02.002

[29] Maarten, H.W., Selfhout, S.J.T., Branje, M., Delsing, T.F.M. and Terbogt, W.H.J. (2009) Different Types of Internet Use, Depression, and Social Anxiety: The Role of Perceived Friendship Quality. Journal of Adolescence, 32, 819-833. http://dx.doi.org/10.1016/j.adolescence.2008.10.011

[30] Motamednejad, K. (2002) UNESCO and the Protection of Children against Internet. Journal of Internet Addiction, 12, 28-33.

[31] Shotton, M. (1997) The Costs and Benefits of Computer Addiction. Behavior and Information Technology, 10, 219230. http://dx.doi.org/10.1080/01449299108924284

[32] Sajadian, A. and Nadi, M.A. (2006) The Relationship between Depression and Social Isolation of Young Internet Users at the Time of Internet Use. Behavioral Sciences Research, 4, 33-38. 